\title{
Validity of the Physical Activity Scale for the Elderly (PASE): according to energy expenditure assessed by the doubly labeled water method.
}

Citation for published version (APA):

Schuit, A. J., \& Schouten, E. G. W. (1997). Validity of the Physical Activity Scale for the Elderly (PASE): according to energy expenditure assessed by the doubly labeled water method. Journal of Clinical Epidemiology, 50(5), 541-546. https://doi.org/10.1016/S0895-4356(97)00010-3

Document status and date:

Published: 01/01/1997

DOI:

10.1016/S0895-4356(97)00010-3

Document Version:

Publisher's PDF, also known as Version of record

Please check the document version of this publication:

- A submitted manuscript is the version of the article upon submission and before peer-review. There can be important differences between the submitted version and the official published version of record.

People interested in the research are advised to contact the author for the final version of the publication, or visit the DOI to the publisher's website.

- The final author version and the galley proof are versions of the publication after peer review.

- The final published version features the final layout of the paper including the volume, issue and page numbers.

Link to publication

\footnotetext{
General rights rights.

- You may freely distribute the URL identifying the publication in the public portal. please follow below link for the End User Agreement:

www.umlib.nl/taverne-license

Take down policy

If you believe that this document breaches copyright please contact us at:

repository@maastrichtuniversity.nl

providing details and we will investigate your claim.
}

Copyright and moral rights for the publications made accessible in the public portal are retained by the authors and/or other copyright owners and it is a condition of accessing publications that users recognise and abide by the legal requirements associated with these

- Users may download and print one copy of any publication from the public portal for the purpose of private study or research.

- You may not further distribute the material or use it for any profit-making activity or commercial gain

If the publication is distributed under the terms of Article $25 \mathrm{fa}$ of the Dutch Copyright Act, indicated by the "Taverne" license above, 
J Clin Epidemiol Vol. 50, No. 5, pp. 541-546, 1997

Copyright (C) 1997 Elsevier Science Inc.

$0895-4356 / 97 / \$ 17.00$

PII S0895-4356(97)00010-3

\title{
Validity of the Physical Activity Scale for the Elderly (PASE): According to Energy Expenditure Assessed by the Doubly Labeled Water Method
}

\author{
Albertine J. Schuit, ${ }^{1, *}$ Evert G. Schouten, ${ }^{1}$ \\ Klaas R. Westerterp, ${ }^{2}$ and Wim H. M. Saris ${ }^{2}$ \\ 'Department of Epidemiology and Public Health, University of Wageningen \\ and ${ }^{2}$ Department of Human Biology, University of Limburg, Tiie Netherlands
}

\begin{abstract}
The study investigates the validity of the Physical Activity Scale for the Elderly (PASE) in 21 Dutch elderly men and women. The PASE is an easily scored, brief questionnaire for elderly, suitable for large epidemiologic studies. The PASE score was compared with physical activity measured with the doubly labeled water method. The correlation coefficient of the PASE score with the residuals from the regression analysis using total encrgy expenditure as dependent and resting metabolic rate as independent variate was $0.58(95 \%$ $\mathrm{CI}=0.50-0.81$ ). Women had greater engagement in extremely high scoring activities as housework and taking care of others, resulting in higher PASE scores than men (97.9 and 71.9). The higher scores in women were not linked to higher activity levels, which suggests that the mentioned activities may be overvalued. Sex specific correlation coefficients were $0.79(\mathrm{CI}=0.32-0.95)$ and $0.68(\mathrm{CI}=0.15-0.90)$ for men and women, respectively. In conclusion, the PASE proved to be a reasonable valid method to classify healthy elderly men and women into categories of physical activity. Some possible refinements were suggested, which may improve the accuracy of the PASE questionnaire. J CLIN EPIDEMIOL 50;5:541-546, 1997. (C) 1997 Elsevier Science Inc.
\end{abstract}

KEY WORDS. Physical activity, questionnaire, validity, elderly

\section{INTRODUCTION}

Epidemiologic studies investigating the effect of physical activity on health, often use questionnaires to assess physical activity. Questionnaires are cheap, not labor consuming, and if valid are a very useful tool to assess physical activity in a general population. Validity of questionnaires is usually examined with pulse records [1], motion sensors, or accelerometers [2-4]. Food intake $[1,2,5]$ or cardiorespiratory fitness and body composition [3] are used as proxies as well. The doubly labeled water (DLW) method, is considered as the gold standard in measuring energy expenditure in freeliving subjects $[6,7]$. However, costs of this method are considerable and it is used only in small-scale studies.

We assessed the validity of the Physical Activity Scale for the Elderly (PASE) developed by the New England Research Institute [8], using the doubly labeled water method. The PASE was used to monitor changes in physical activity among elderly participating in a controlled intervention study, which investigated the cardiovascular response to regular physical activity. The PASE is designed to assess

\footnotetext{
"Address for correspondence: Albertine J. Schuit, Department of Epidemiology and Public Health, University of Wageningen, P.O. Box 238, 6700 AE Wageningen, The Netherlands.

Accepted for publication un 30 January 1997.
}

activities commonly engaged in by elderly persons. It assesses the activity of the past week, enabling detection of changes in activity over a relatively short period of time. The questionnaire does not estimate energy cxpenditure, like most questionnaires do, but produces a score with which subjects can be compared. However, the questionnaire was designed for American elderly, who have a slightly different life style compared to Dutch elderly. We therefore adjusted the PASE questionnaire and tested its validity among 21 elderly men and women with the doubly labeled water method.

\section{SUBJECTS AND METHODS Subjects}

The subjects of this study were recruited from the participants of an intervention study, which was four months underway. The participants were residents of Arnhem, a middle-sized city in The Netherlands. All elderly, age range 60 to 80 years, met the inclusion criteria for the intervention study: no heart failure, no angina pectoris, no insulin dependent diabetes mellitus, no use of beta-blockers, and no myocardial infarction or stroke in the past 2 years. Subjects taking diuretic drugs that could influence hydration were excluded from the study, as this might influence the DLW 
measurement. At the entrance of the intervention study the PASE questionnaire was administered among all participants. Based on tertiles of the PASE score, the total population was stratified in low, middle, and high activity groups, men and women separately. From each of these groups, subjects were selected in equal numbers from intervention and control group for a total of 22. Thus a broad range of activities could be expected. Three subjects refused participation because of time restraints, therefore a peer from the same group was approached. One man dropped out a few days before the study started, leaving us with 10 men and 11 women. Subjects of the intervention group gathered three times a week for 45 minutes performing aerobic exercise, calisthenics, and flexibility exercises.

\section{Measurements}

The validity of the PASE was assessed by comparing the PASE score with two measures of physical activity, namely (1) the physical activity ratio (PAR) which is the ratio of total energy expenditure (TEE) and resting metabolic rate (RMR) and traditionally and widely used and (2) the residual of the regression with TEE as dependent and RMR as independent parameter, as was recently recommended [9]. TEE was measured with the DLW method over a 2-week period and RMR was measured with a ventilated hood. Since change in body weight may affect the TEE measurement, body weight was measured before and after the measurement period. The PASE questionnaire was administered in the second week of the energy expenditure measurcment with the DLW method.

PASE QUESTIONNAIRE. The PASE questionnaire is a brief, easy tool for the assessment of short-term physical activity in epidemiologic studies of elderly. It comprises activities commonly engaged in by elderly persons, and does not emphasize sport and recreational activities, as do most other questionnaires. Also, the reference period is shorter (one week) than other questionnaires. The rationale for this is that elderly generally have more problems recalling activities of a long time ago and that elderly are prone to changes in activities due to problems with physical or mental well being. A drawback, however, is that a single PASE score does not always reflect habitual activity. It is very liable to external influences such as weather conditions. Sitting activities, walking, cycling, recreational and sport activities (divided in light, medium, and heavy) are recorded as never, seldom (1-2 days/week), often (3-4 days/week), and mostly (5-7 days/week). Duration is categorized in less than 1 hour, between 1 and 2 hours, between 2 and 4 hours, and more than 4 hours per week, with exception of paid/unpaid work, which is recorded in total hours per week. Housework (light and heavy), lawn work, home repair, gardening, and caring for others are recorded as either performed or not, so no frequency or duration is asked. The total PASE score can be computed by multiplying the amount of time spent in each activity (hr/week) by the item weights and summing over all activities. The item weights are originally based on comparison with physical activity estimated with 3-day motion sensor counts, 3-day physical activity diary, and global activity assessment [8].

MODification OF THE PASE. The PASE questionnaire was slightly adjusted for use in Dutch elderly. Bicycling is a very common activity among elderly in The Netherlands, both for transportation and for recreational purposes. We thereforc added bicycling for transportation to the question in which time spent on walking was asked. We considered this legitimate since walking and bicycling have similar metabolic values [10]. Brisk walking and bicycling for recreational purposes were listed among moderate sport and recreational activities, as was done in the original version of the questionnaire. The PASE divides gardening into heavy lawn work and outdoor gardening. In the category heavy lawn work we added digging and working in a vegetable garden. Finally, morning gymnastics (stretching with some light strength training) was added to the light sport and recreational activities.

TOTAL ENERGY EXPENDITURE BY DLW METHOD. Total energy expenditure over a 2 -week period was measured with the DLW method using the Maastricht protocol [11]. Comparing this technique with calorimetry $[7,8]$ showed that it provided high levels of accuracy and precision (4-6\%) in a wide range of subjects. A great advantage of this method is that it measures energy expenditure over a 2 -week period and does not interfere with a subjects' usual activity.

In our study all subjects were visited at home between 9:00 and 11:00 p.m. to collect a background urine sample, before the isotope dose was administered. Every subject received a dose according to their total body water. The dose consisted of $10 \mathrm{At} \% \mathrm{H}_{2}{ }^{18} \mathrm{O}$ and $5 \mathrm{At} \%{ }^{2} \mathrm{H}_{2} \mathrm{O}$ resulting in an initial excess body water enrichment of $150 \mathrm{ppm}$ for ${ }^{2} \mathrm{H}$ and $300 \mathrm{ppm}$ for ${ }^{18} \mathrm{O}$, leaving a sufficient excess enrichment at the end of the 2-week observation period. The subjects drank the labeled water straight from the bottle (with a straw). The bottle was rinsed with some tap water, which was consumed as well. The next day, 1 week later, and 2 weeks later, urine was collected before 9:00 a.m. (the second voiding of the morning) and between 9:00 and 11:00 p.m. The utine was sampled and stored at $-20^{\circ} \mathrm{C}$ on the day of collection. Urine samples were analyzed with isotope ratio mass spectrometry (Aqua Sira, VG, U.K.). ${ }^{18} \mathrm{O}$ was measured in water vapor, produced by on-line vacuum distillation, ${ }^{2} \mathrm{H}$ was measured in hydrogen gas, produced online by hot uranium technique [12].

RESTING METABOLIC RATE. Just before the start and at the end of the 2-week study period subjects were brought to the laboratory of Wageningen Agricultural University before 9:00 a.m., after an overnight fast. Resting metabolic 
rate was measured by indirect calorimetry [13] using an open-circuit ventilated hood system. The transparent hood with an air inlet on top and an air outlet at the right side was placed over the head of the subject. Through the hood fresh filtered outside ait was drawn by a pump (SCL210, Ocean, Dieren, The Netherlands). The air flow was measured by a thermal mass flow meter $(5812 \mathrm{~N}$, Brooks, Veenendaal, The Netherlands) and maintained at $40 \mathrm{~L} / \mathrm{min}$ by a control valve (5837, Brooks). Gas analyses were performed with, respectively, an infrared carbon dioxide analyzer (1410, Servomex, Zoetermeer, The Netherlands) and a paramagnetic oxycon analyzer (1100A, Servomex). Dried standard gas and dried filtered fresh atmospheric air were used to calibrate the analyzers. The span point of the oxygen analyzer was controlled and was recalibrated every $60 \mathrm{~min}$. Flow rate, carbon dioxide, and oxygen concentrations were integrated over 2-min intervals. Metabolic rate was calculated using Weir's equation [14]. Periodical alcohol combustion was used as a reference to which all measurements were standardized. The reproducibility of the ventilated hood measurements was determined by six alcohol combustion tests for each ventilated hood, carried out un separate days over 2 weeks (average RQ: $0.655 \pm \mathrm{SD} 0.015$ ). The measurement was done under standardized conditions, with the subjects lying half supine in a thermoneutral room (temperature $21 \pm 2^{\circ} \mathrm{C}$ ) and watching nonstressing movics. The subjects were instructed to avoid heavy physical activity on the morning of the measurement. Subjects were asked to remain awake and motionless during the measurement. Metabolic rate was measured continuously for $60 \mathrm{~min}$, but the mean energy expenditure of the last $45 \mathrm{~min}$ were used as the RMR. The 14 days within-person variation of RMR was $3.3 \%$ for women and $3.7 \%$ for men. For the data analyses mean RMR was used.

BODY COMPOSITION. Body mass was measured at the beginning and end of the study period, to the nearest 0.05 $\mathrm{kg}$ using a digital scale (ED60-T, Berkel, Rotterdam, The Netherlands), after voiding, with subjects wearing only light underwear. Body mass index was calculated as body weight $(\mathrm{kg})$ divided by height $(\mathrm{m})$ squared. Total body water (TBW) was measured with deuterium dilution, using a 10 . hr equilibration interval. Previous research showed that this method had no significant differences with underwater weighing (mean difference: $-1.1 \% \pm 0.7 \%$ ) [11]. Fat free mass was calculated as TBW divided by 0.732 . Body fat was calculated as body weight minus fat free mass.

\section{DATA ANALYSIS}

Mean values of age, body mass index, and percentage body fat derived from the deuterium dilution technique, were calculated for men and women separately. For each subject the PASE score was calculated and mean values for men and women were computed. To assess the contribution of each activity item, we calculated the mean time expenditure per activity in the total group and multiplied the mean with the item weight. A regression analysis was performed in men and women combined, with energy expenditure as dependent and resting metabolic rate as independent variate, to calculate the residuals. The residuals represent the difference of the actual value with the predicted value of energy expenditure, according to RMR. A negative residual indicates that a subjects' energy expenditure was lower than would be expected by the regression model, which is based on the total group. The correlation of PAR and residual with the PASE score were calculated. Because of nonnormality of the PASE score, Spearman correlation coefficients were used.

\section{RESULTS}

Table 1 shows the baseline characteristics of the study population. Men were slightly older and had a lower PASE score than women. The higher PASE score of women was mainly due to a more frequent participation in heavy housework ( 8 versus 1) and taking care of other ( 3 versus 0 ) (for relative contribution of activities to the PASE score see Table 2). Although PAR was similar for men $(1.78 \pm 0.22)$ and women $(1.85 \pm 0.23)$, women had lower residuals in the regression analysis with TEE (MJ/day) as dependent and RMR (MJ/day) as independent variate (Fig. 1). The regression line had an intercept of 4.08 (SE - 1.4), and a beta for RMR of 1.11 ( $\mathrm{SE}=0.23$ ). Table 2 gives an overview of the various activities included in the PASE questionnaire. For each activity, average time expenditure or proportion of participants involved, item weight, and contribution to the mean PASE score are presented, for men and women combined. In our population walking, cycling, and light housework were the major components of the PASE score. Figure 2 shows a plot of the significant correlation between the PASE score and PAR $(p<0.01)$. The Spearman corre-

TABLE 1. Baseline characteristics (mean and standard deviation) of the participants

\begin{tabular}{lccccr}
\hline & \multicolumn{2}{c}{$\begin{array}{c}\text { Men } \\
(n=10)\end{array}$} & & \multicolumn{2}{c}{$\begin{array}{c}\text { Women } \\
(\boldsymbol{n}=\mathbf{1 1})\end{array}$} \\
\cline { 2 - 3 } Characteristic & Mean & SD & & Mean & SD \\
\hline Age (years) & 70.6 & 3.8 & & 69.2 & 4.8 \\
Body mass index $\left(\mathrm{kg} / \mathrm{m}^{2}\right)$ & 26.3 & 2.2 & & 24.3 & 3.0 \\
Body fat (\%) & 29.5 & 0.5 & & 34.4 & 5.4 \\
PASE score & 71.9 & 26.8 & 97.9 & 45.9 \\
No. of smokers & 1 & & & 1 & \\
No. of cigarettes/week & 175 & 0.0 & 175 & 0.0 \\
No. of alcohol con- & 8 & & & 5 & \\
$\quad$ sumers & 3.0 & 1.1 & & 2.2 & 1.6 \\
No. of drinks/week & 7 & & & 7 & \\
No. of sporters & 270.0 & 155.9 & & 244.3 & 92.4 \\
min/week & & & & &
\end{tabular}


TABLE 2. PASE activities, performance, weight score, and contribution to the PASE score of the total group

\begin{tabular}{llcr}
\hline PASE activity & Performance & $\begin{array}{c}\text { Item } \\
\text { weight }\end{array}$ & $\begin{array}{c}\text { Contribution } \\
\text { PASE }\end{array}$ \\
\hline Walking and bicycling & 1.10 hour/day & 20 & 22.0 \\
Light SRA & 0.08 hour/day & 21 & 1.68 \\
Moderate SRA & 0.12 hour/day & 23 & 2.76 \\
Heavy SRA & 0.19 hour/day & 23 & 4.37 \\
Muscle strength/endurance & 0.0 hour/day & 30 & 0 \\
Paid/unpaid work & 0.30 hour/day & 21 & 6.3 \\
Light housework & $95.2 \%$ & 25 & 23.8 \\
Heavy housework & $42.9 \%$ & 25 & 10.73 \\
Home repairs & $9.5 \%$ & 30 & 2.85 \\
Lawn work & $9.5 \%$ & 36 & 3.42 \\
Gardening & $4.8 \%$ & 20 & 0.96 \\
Caring for others & $19.0 \%$ & 35 & 6.65 \\
Total activity & & & PASE score 85.5 \\
\hline
\end{tabular}

${ }^{a} \mathrm{SRA}=$ Sport and recreational activities.

lation coefficient between PAR and PASE score was for the total group $0.68(95 \% \mathrm{CI}=0.35-0.86)$, for men 0.78 $(\mathrm{Cl}=0.31-0.95)$ and women $0.59(\mathrm{CI}=0.00-0.88)$. Figure 3 shows a plot of the PASE score with the residuals of the regression TEE $=$ RMR. The Spearman correlation coefficient of the PASE score with the residuals of the regression analysis was $0.58(\mathrm{Cl}=0.50-0.81)$ in the total population and statistically significant. For men and women separately it was $0.79(\mathrm{CI}=0.32-0.95)$ and $0.68(\mathrm{CI}=$ 0.15-0.90), respectively.

Both Higs 2 and 3 show that PASE can distinguish into categories of physical activity, but the outliers show that PASE does not reflect exact actual metabolic activity. Figure 3 clearly shows an overestimation of PASE scores in women as compared to men, indicating that sex specific activities such as housework and taking care of others may be overvalued in the PASE score.

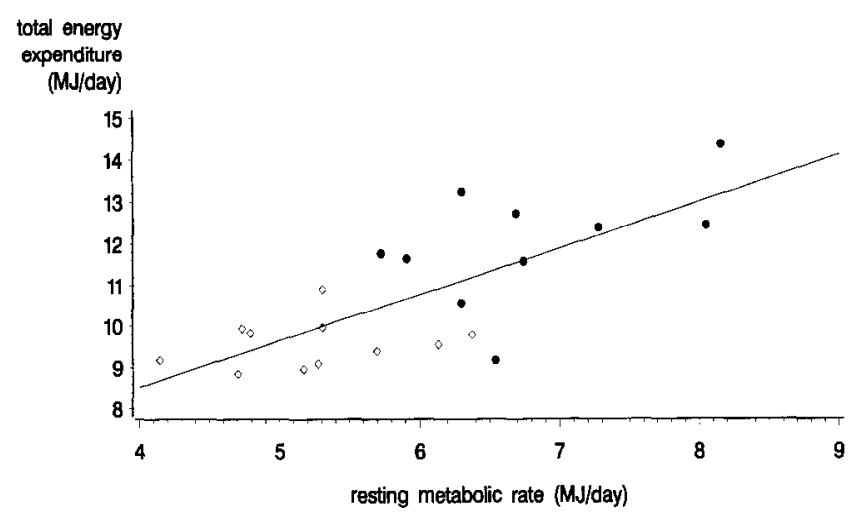

FIGURE 1. Regression analysis with resting metabolic rate (RMR) as independent and total energy expenditure (TEE) as dependent variate. Gender: men (solid circles) and women (open diamonds); $\mathrm{y}=1.11 \mathrm{x}+4.08$.

\section{DISCUSSION}

The PASE questionnaire is an easily scored, quick tool to assess physical activity in an elderly population. PAR (TEE/ RMR) as well as the residuals from the regression analysis with TEE as dependent and RMR as independent were used as measures of physical activity. Both measures were significantly correlated with the PASE score $(r=0.68$ and $r=$ 0.58 , respectively), indicating that PASE discriminates categories of physical activity reasonably well and therefore is suitable for epidemiologic studies. However, PASE does not accurately measure individual metabolic activity.

\section{Energy Expenditure}

Lately there has been some discussion on what would be the best way to correct TEE by RMR in order to estimate

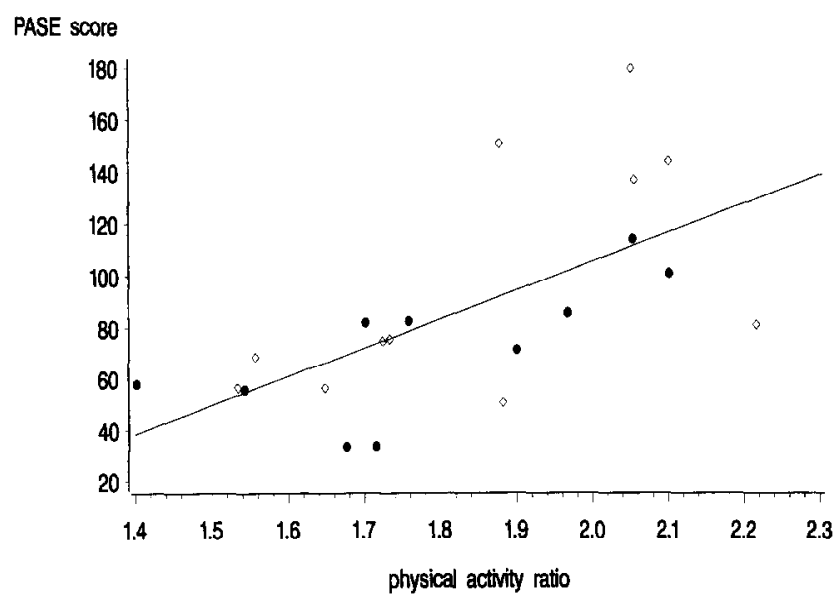

FIGURE 2. Correlation of PASE score with physical activity ratio (PAR). Gender: men (solid circles), women (open diamonds); $\mathrm{n}=0.68(\mathrm{CI}=0.35-0.86)$. 


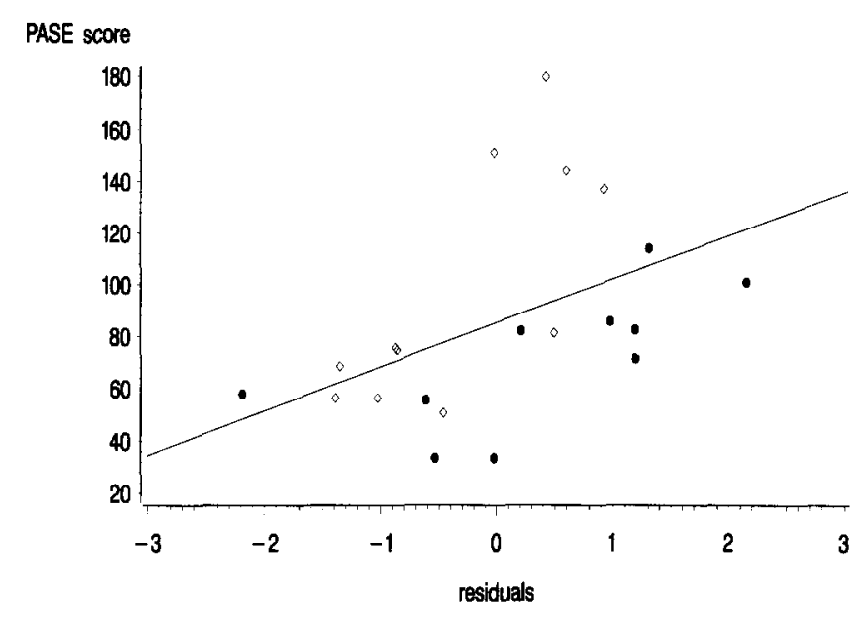

FIGURE 3. Correlation of PASE score with residuals of regression with RMR as independent and TEE as dependent variate. Gender: men (solid circles), women (open diamonds $) ; \mathrm{r}=0.58(\mathrm{Cl}=0.50-0.81)$.

physical activity $[9,15]$. Carpenter [9] has suggested the use of residuals of the regression TEE $=\mathrm{RMR}$, rather than the ratio TEE/RMR for comparison of physical activity between subjects, because the regression line of TEE and RMR generally does not pass through the origin. Cole and colleages [15], on the other hand, showed that the ratio truly is a valid index of TEE corrected for RMR, using data from a group of 574 adults and children. In our study the intercept was significantly different from zero in buth the linear and the log-log model. Consequently, PAR may overestimate physical activity in subjects of our group with a low RMR (women) as compared to subjects with a high RMR (men). We thereforc belicve that use of the residual method is more appropriate for comparison of physical activity in our study than use of PAR. We still present PAR in this article because it is widely used.

\section{PASE Score}

Women in our study population had higher PASE scores than men. The mean difference in PASE score between men and women was mainly due to a greater engagement of women in heavy housework and taking care of others, which added respectively 25 and 35 points to the score. However, the RMR-adjusted energy expenditure levels of women were not higher than men. This may indicate that the PASE questionnaire overestimates womens' physical activity as compared to men, due to an incorrect weighing of heavy housework and caring for others. We therefore conducted an additional analysis in which we assigned successively one half and one quarter of the original item weight to these activities. As expected, the correlation coefficients improved with both measures to 0.68 and 0.71 , respectively, for one half the item weight and 0.71 and 0.74 for one quarter of the item weight, men and women combined. The difference in mean PASE score between men and women resulted in a weaker correlation between PASE score and the residuals in the total group as compared to the gender specific correlations.

The stronger correlation between PASE score and PAR, as compared to the residuals, in the total group can be explained by a concomitant higher PASE score and higher PAR in women. Washburn et al. [8] report higher PASE scores for men than women in both younger and older elderly. The difference with our study group may be explained by a more equal division of heavy housework and taking care of others among American men and women, or by a greater engagement of American men in gardening, which is designated to a score comparable to heavy housework. The article reports a higher engagement of American elderly in lawn work ( 45.6 versus $9.5 \%$ ) and outdoor gardening ( 26.8 versus $4.8 \%)$ as compared to our population and although no gender specific data are presented, it is likely that men more frequently perform gardening activities than women. Our study was carried out in the winter period during which hardly any garden work is performed. Compared to the American elderly, the elderly in our population spent more time on walking (and bicycling) per day $(1.10 \mathrm{hr}$ versus $0.65 \mathrm{hr})$ and on strenuous sport activity $(0.19 \mathrm{hr}$ versus $0.07 \mathrm{hr}$ ), the latter partly due to the intervention program. Strenuous activity does not highly contribute to the PASE scorc (an hr of heavy sport activity per week, for example, results only in 3.3 extra points), but this seems justified, because in our study group it also did not significantly affect total energy expenditure. Taking item weights two or three times higher for heavy sport activity did not produce higher correlation coefficients. It might be argued that the physical activity of the intervention was not sufficiently represented in the PASE score of the intervention subjects. However, total energy expenditure on physical activity was not different between intervention and control subjects (PAR: both groups 1.82 , residuals intervention 0.14 , control -0.15 ). Thus, it seems that the intervention program did not disturb the performance of the PASE.

\section{CONCLUSION}

The PASE questionnaire proved to be a reasonably valid method to classify healthy elderly people into levels of physical activity. We do believe, however, that if time spent on gardening, housework, and taking care of others, were taken into account in calculation of the score (similar to calculation of sport and recreational activities) or if the item weights of these activities were reduced, classification would be even better. This might also prevent overvaluation of gender specific tasks, such as housework and gardening. Although the PASE score does not reflect actual metabolic activity, it may be very useful for characterizing physical activity level in large epidemiologic studies. However, because some highly contributing activities may be different between populations (i.e., outdoor activities can only be 
performed under good weather conditions, or distribution of household tasks), one should also be cautious in comparing PASE scores among populations with different backgrounds.

We thank the participants from Amhem for their cooperation. The authors gratefully acknowledge Frans Schouten for conducting the resting metabolic rate measurements and Jan Burema for his statistical advice. This study was performed with the financial support of the Dutch Heart Foundation.

\section{References}

1. Sallis JF, Buno MJ, Roby JJ, Micale FG, Nelson JA. Sevenday recall and other physical activity self-reports in children and adolescents. Med Sci Sports Exerc 1993; 25: 99-108.

2. LaPorte RE, Black-Sandler R, Cauley JA, Link M, Bayles C, Marks B. The assessment of physical activity in older women: Analysis of the interrelationship and reliability of activity monitoring, activity surveys, and caloric intake. J Geront 1983; 38: 394-397.

3. Ainsworth BE, Jacobs DR, Leon AS. Validity and reliability of self-reported physical activity status: The Lipid Research Clinics questionnaire. Med Sci Sports Exerc 1993; 25: $92-$ 98.

4. Haskell WL, Yee MC, Evans A, Irby PJ. Simultaneous measurement of heart rate and body motion to quantitate physical activity. Med Sci Sports Exerc 1993; 25: 109-115.

5. Arroll B, Jackson R, Beaglehole R. Validation of a threemonth physical activity recall questionnaire with a seven-day food intake and physical activity diary. Epidemiology 1991; 2: 296-299.

6. Westerterp KR, Brouns F, Saris WHM, ten Hoor F. Compari- son of doubly labeled water with respirometry at low- and high-activity levels. J Appl Physiol 1988; 65: 53-56.

7. Schoeller DA, Ravussin E, Schultz Y, Acheson KJ, Baertschi $P$, Jéquier $E$. Energy expenditure by doubly labeled water: $\mathrm{Val}$ idation in humans and proposed calculation. Am J Appl Physiol 1986; 250: R823-R830.

8. Washburn RA, Smith KW, Jette AM, Janney CA. The physical activity scale for the elderly (PASE): Development and cvaluation. J Clin Epidemiol 1993; 46: 153-162.

9. Carpenter WH, Poehlman ET, O'Connell M, Goran MI. Influence of body composition and resting metabolic rate on variation in total energy expenditure: A meta-analysis. Am J Clin Nutr 1995; 61: 4-10.

10. Ainsworth BE, Haskell WL, Leon $\triangle \mathrm{S}$, Jacons DR, Montoye HJ, Sallis JF, Paffenbarger RS. Compendium of physical activity: Classification of energy costs of human physical activities. Med Sci Sports Exerc 1993; 25: 71-80.

11. Westerterp KR, Wouters I, Marken Lichtenbelt van WD. The Madastricht protocol for the medsurement of body composition and energy expenditure with labeled water. Obesity Research 1995; 3: 49-57.

12. Wong WW, Klein PD. A review of techniques for the preparation of biological samples for mass-spectrometric measurements of hydrogen-2/hydrogen-1 and oxygen-18/oxygen-16 isotope ratios. Mass Spec Rev 1986; 5: 313-342.

13. Weststrate JA. Resting metabolic rate and diet-induced thermogenesis: A methodological reappraisal. Am J Clin Nutr 1993; 58: 592-601.

14. Weir JBV. New methods for calculating metabolic rate with special reference to protein metabolism. J Physiol 1949; 109: $1-9$.

15. Cole TJ, Black AE, Coward WA, Prentice AM. Total energy expenditure and basal metabolic rate. Am J Clin Nutr 1996; 63: 281 